\title{
Kajian Timbulan Limbah Infeksius Rumah Sakit Kota Bandung dan Cimahi
}

\section{Study of Hospital Infectious Waste Generation in Bandung and Cimahi City}

\author{
VENNY ULYA BUNGA DAN ENRI DAMANHURI \\ Program Studi Teknik Lingkungan, Institut Teknologi Bandung, Jl. Ganesha No. 10 Bandung 40132 \\ Email: venulbunga@gmail.com
}

\begin{abstract}
The increased activities in hospitals will increase the infectious waste generation. The infectious waste contains pathogenic organisms that can spread disease to humans and the environment. The harmful impact of infectious waste can be minimized through proper waste management, starting from waste generation. This study aims to examine the problem of infectious waste generation: the overall percentage of infectious waste generation in hospitals, the amount of infectious waste generation from each source (processing unit), and analyze factors that significantly affected its generation. This study is expected to be the basis of recommendations for hospitals in handling infectious waste. The study was conducted in four public hospitals in Bandung and Cimahi City. The data consists of infectious waste generation, non-infectious waste (general waste) generation, and hospital data as data factors analyzed for its influence on waste generation. The stepwise regression method was used for factor analysis with $95 \% \mathrm{Cl}$. The result showed that infectious waste generation had a lower percentage than non-infectious waste, ranging from $38-47 \%$. The treatment rooms that produce the most considerable infectious waste are haemodialysis, operating rooms and inpatients with an average infectious waste generation of 0,08$2,18 \mathrm{~kg} /$ patient/day. Thus, the three rooms can become a priority for infectious waste management. Factors that significantly affect the generation of infectious waste are dominated by patients and medical personnel. The importance of this factor is related to waste sorting activities. Therefore, special control by hospital management is needed for these two factors.
\end{abstract}

Keywords: hospital, generation, infectious waste, treatment room, factors

\begin{abstract}
ABSTRAK
Peningkatan aktivitas rumah sakit akan diikuti dengan peningkatan timbulan limbah infeksius. Limbah infeksius mengandung organisme patogen yang dapat menyebarkan penyakit bagi manusia dan lingkungan. Dampak limbah infeksius dapat diminimalisir melalui kegiatan pengelolaan limbah yang tepat, dimulai dari timbulan limbah. Penelitian ini bertujuan mengkaji secara mendalam hal seputar timbulan limbah infeksius, dimulai dari persentase timbulan limbah infeksius rumah sakit secara keseluruhan, besaran timbulan limbah infeksius dari setiap sumber (unit perawatan) serta analisa terhadap faktor yang memiliki pengaruh signifikan terhadap timbulan limbah. Kajian ini diharapkan dapat menjadi dasar rekomendasi untuk pengelolaan limbah infeksius rumah sakit. Penelitian dilakukan di empat rumah sakit umum area Kota Bandung dan Cimahi. Data penelitian terdiri atas timbulan limbah infeksius dan noninfeksius (limbah umum) serta data atribut rumah sakit sebagai data faktor yang dianalisis pengaruhnya terhadap timbulan limbah. Analisis faktor menggunakan metode stepwise regression dengan signifikansi $0,05(95 \% \mathrm{Cl})$. Hasil penelitian menunjukkan limbah infeksius memiliki persentase timbulan yang lebih kecil dibandingkan limbah non-infeksius (limbah umum) yaitu kisaran 38-47\%. Unit perawatan yang menjadi penghasil limbah infeksius terbesar berasal dari unit haemodialisa, kamar operasi serta rawat inap dengan kisaran rata-rata besaran timbulan limbah infeksius sebesar 0,08-2,18 kg/pasien/hari. Dengan demikian, ketiga unit perawatan tersebut dapat menjadi prioritas pengelolaan limbah infeksius. Adapun faktor yang berpengaruh signifikan terhadap timbulan limbah infeksius didominasi oleh faktor jumlah pasien dan jumlah staf medis. Signifikan faktor ini berkaitan dengan kegiatan pemilahan limbah sehingga perlu pengendalian khusus oleh pihak rumah sakit terhadap kedua faktor tersebut.
\end{abstract}

Kata kunci: rumah sakit, timbulan, limbah infeksius, unit perawatan, faktor 


\section{PENDAHULUAN}

\subsection{Latar Belakang}

Berdasarkan Peraturan Pemerintah Nomor 47 tahun 2016, fasilitas pelayanan kesehatan di Indonesia terdiri atas rumah sakit, pusat kesehatan masyarakat (puskesmas), klinik, apotek, laboratorium, unit transfusi darah, fasilitas kesehatan tradisional, serta tempat praktik mandiri tenaga kesehatan. Rumah sakit, menurut Undang-Undang Nomor 44 tahun 2009, merupakan institusi kesehatan yang memberikan pelayanan kesehatan secara paripurna, terdiri atas pelayanan rawat inap, rawat jalan dan gawat darurat. Hal ini membuat tingginya aktivitas rumah sakit dalam rangka pemenuhan pelayanan kesehatan masyarakat. Tingginya aktivitas rumah sakit ini di satu sisi berdampak pada lingkungan dimana jumlah limbah yang dihasilkan pun semakin banyak. Menurut WHO, total limbah yang dihasilkan fasilitas kesehatan termasuk rumah sakit, $75-90 \%$ diantaranya berupa limbah umum (limbah non medis) dan 10-25\% limbah medis $^{(1)}$. Di Indonesia melalui Peraturan Pemerintah Nomor 22 tahun 2021 (sebagai pengganti Pearturan Pemerintah Nomor 101 tahun 2014) tentang Pengelolaan Limbah Berbahaya dan Beracun (B3), limbah medis didefinisikan sebagai limbah B3 yang bersifat infeksius (Lampiran X). Limbah infeksius merupakan limbah yang terkontaminasi organisme patogen dan mampu menularkan penyakit pada manusia(1). Meskipun limbah infeksius memiliki porsi yang relatif kecil dibandingkan limbah umum (non-infeksius atau limbah domestik), pengelolaan limbah infeksius dianggap sebagai isu global lingkungan yang perlu diperhatikan. Ketika limbah infeksius tidak dipisahkan dari sumber sesaat setelah limbah tersebut dihasilkan dan tercampur dengan limbah umum, maka limbah tersebut menjadi 100\% limbah infeksius ${ }^{(2)}$. Limbah infeksius sendiri disebut sebagai limbah berbahaya (hazardous waste) oleh karena resikonya yang tinggi terhadap kesehatan lingkungan. Risiko kesehatan tersebut salah satunya terjadi peningkatan penyakit menular seperti AIDS, Hepatitis B dan $C^{(3)}$.

Dalam rangka meminimalisir risiko yang ditimbulkan limbah infeksius maka harus memaksimalkan upaya pengelolaan limbah medis yang tepat secara keseluruhan. Pengelolaan limbah tersebut dapat dimulai dari kegiatan pengelolaan jumlah limbah yang dihasilkan atau dalam istilah lingkungan dikenal sebagai timbulan limbah. Timbulan limbah pun telah lama menjadi kajian utama untuk pengelolaan limbah secara keseluruhan. Masalah utama dari pengelolaan limbah ialah terletak pada berapa banyak limbah dihasilkan(4).
Penelitian terhadap laju timbulan limbah dapat menjadi dasar untuk mengembangkan metode minimasi limbah dan program pengelolaan limbah yang efektif(5). Dengan demikian penting untuk mengkaji secara mendalam mengenai timbulan limbah. Khusus terkait timbulan limbah medis infeksius rumah sakit, kajian yang dapat dilakukan terdiri atas nilai besaran timbulan limbah infeksius, sumber penghasil limbah infeksius serta faktor apa yang memengaruhi besaran timbulan limbah tersebut. Berdasarkan penelitian sebelumnya, faktor jumlah pasien dan praktik pengelolaan limbah infeksius juga turut memengaruhi timbulan limbah infeksius ${ }^{(6)}$. Selain kedua faktor tersebut, faktor jumlah staf medis dan manajemen rumah sakit pun dapat berpengaruh pada timbulan limbah infeksius ${ }^{(7)}$.

Penduduk kota Bandung pada tahun 2019 adalah 2.480.464 jiwa (BPS kota Bandung, update terakhir 18 Maret 2021). Di satu sisi, jumlah penduduk Kota Cimahi pada 2019 sebanyak 614.304 orang (BPS Kota Cimahi, update terakhir 26 Mei 2020). Berdasarkan kondisi kependudukan di dua wilayah tersebut, diprediksikan akan terjadi peningkatan aktivitas fasilitas pelayanan kesehatan khususnya rumah sakit. Hal ini berdampak akan meningkatnya jumlah limbah medis di kedua kota tersebut. Peningkatan jumlah penduduk menyebabkan peningkatan aktivitas penduduk yang berarti juga terjadi peningkatan jumlah timbulan limbah. Kajian khusus tentang timbulan limbah infeksius di Bandung dan Cimahi belum banyak dilakukan. Oleh karena itu, diharapkan melalui penelitian ini dapat menjadi referensi baru bagi pihak rumah sakit di kedua kota dalam rangka melakukan pengelolaan limbah infeksius dan limbah medis rumah sakit secara keseluruhan.

\subsection{Tujuan Penelitian}

Tujuan dari penelitian ini yakni mendapatkan informasi komprehensif mengenai timbulan limbah infeksius di beberapa rumah sakit Kota Bandung dan Cimahi, yang terdiri atas persentase limbah infeksius dari total keseluruhan limbah padat rumah sakit, besaran timbulan limbah infeksius rumah sakit dari seluruh unit perawatan, dan faktor yang berpengaruh signfikan terhadap timbulan limbah infeksius. Dengan demikian, informasi-informasi tersebut dapat menjadi dasar rekomendasi pengelolaan limbah infeksius rumah sakit. Rekomendasi berupa penentuan prioritas rumah sakit dalam pengelolaan limbah infeksius baik dalam hal prioritas pengelolaan sumber penghasil limbah serta prioritas pengendalian faktor yang berpengaruh signifikan terhadap timbulan limbah infeksius. 


\section{BAHAN DAN METODE}

\subsection{Bahan dan Alat}

Alat yang digunakan dalam penelitian ini antara lain timbangan gantung digital dengan ketelitian 0,01 kg untuk mengukur berat timbulan limbah infeksius serta alat pelindung diri (APD) diantaranya masker, body cover dan sarung tangan saat handling limbah.

Bahan utama penelitian yaitu limbah infeksius asli yang langsung dikumpulkan dari tiap unit perawatan masing-masing rumah sakit (RS). Dalam rangka mendapatkan data timbulan limbah infeksius yang sevalid mungkin, peneliti melakukan koordinasi dengan pihak rumah sakit agar dilakukan pemilahan limbah infeksius dari limbah umum (limbah domestik) dengan membedakan warna plastik limbah (kuning untuk infeksius dan hitam untuk limbah umum).

\subsection{Metode}

\subsubsection{Survei dan Penentuan Lokasi Sampling}

Survei dilakukan dengan metode observasi secara umum terkait timbulan dan pengelolaan limbah infeksius di beberapa RS kota Bandung dan Cimahi serta wawancara tidak terstruktur dengan pihak pengelola limbah RS. Output kegiatan survei ini ialah penentuan beberapa RS yang menjadi sampel penelitian yaitu RS A, RS C, RS D di Kota Bandung dan RS B di Kota Cimahi. Keempat RS merupakan RS Umum. Penentuan sampel ini pada dasarnya ditentukan oleh dua hal yaitu izin penelitian dari RS bersangkutan serta perhitungan minimum sampel dengan Rumus Slovin pada Persamaan 1 berikut:

$$
\mathrm{n}=\frac{N}{1+\left(N \cdot e^{2}\right)}
$$

Keterangan :

$\mathrm{n}=$ jumlah minimum sampel

$\mathrm{N}=$ jumlah populasi

e $=$ persentase tingkat error yang dapat ditolerir (penelitian ini menggunakan error 5\%)

Indikator pelayanan kesehatan RS adalah pemakaian tempat tidur untuk perawatan pasien yang dikenal dengan istilah bed occupancy rate (BOR). Oleh karena itu, perhitungan minimum RS yang diambil menjadi sampel penelitian didasarkan pada jumlah tempat tidur atau beds yang dimiliki RS serupa (RS Umum) di Kota Bandung dan Cimahi. Data Dinas Kesehatan Kota Bandung dan Cimahi Tahun 2017, total beds seluruh RS Umum Kota Bandung dan Cimahi masing-masing 4.280 dan 941 beds. Berdasarkan perhitungan Rumus Slovin, jumlah minimum beds untuk dijadikan sampel yakni 366 (Kota Bandung) dan 281 (Kota Cimahi). RS A,
RS C dan RS D di Kota Bandung memiliki 442 beds dan RS B di Kota Cimahi memiliki 561 beds. Dengan demikian, keempat RS sampel tersebut telah memenuhi persyaratan minimum sampel.

Selain penentuan lokasi sampling, output survei juga berupa list faktor yang akan dikaji pengaruhnya terhadap penghasilan dan besaran timbulan limbah infeksius RS. Faktor-faktor ini dinilai memiliki pengaruh langsung terhadap timbulan limbah infeksus ini yang didapatkan berdasarkan irisan dari hasil kajian studi literatur dari penelitian serupa serta survei lapangan. Faktor-faktor yang dimaksud antara lain:

a. Faktor Jumlah Pasien

b. Faktor Jumlah Staf Medis

c. Faktor Nilai Bed Occupancy Rate (BOR) (khusus unit rawat inap)

\subsubsection{Pengumpulan Data}

Pengumpulan data di RS dilakukan pada Juni-Juli 2018. Data yang dikumpulkan terdiri atas data primer dan data sekunder. Data primer meliputi besaran timbulan limbah padat RS yang terdiri dari limbah infeksius dan limbah umum (limbah domestik). Data timbulan limbah ialah data laju timbulan dalam satuan $\mathrm{kg} /$ pasien/hari sesuai dengan Persamaan 2 berikut.

$$
\frac{\text { Rata-rata timbulan limbah infeksius......... }}{\text { Rata-rata jumlah pasien }}
$$

Keterangan :

Rata-rata timbulan limbah dan jumlah pasien tiap unit perawatan selama tujuh hari

Pengukuran timbulan limbah dilakukan selama tujuh hari berturut-turut dan diukur dalam kurun waktu per 24 jam dengan menyesuaikan waktu pengumpulan limbah di masing-masing RS Metode pengukuran timbulan limbah ini mengacu pada penelitian serupa sebelumnya ${ }^{(1,6)}$. Limbah padat RS yang akan diukur timbulannya berasal dari seluruh kegiatan perawatan masing-masing RS yaitu :

a. Rawat Inap (Seluruh unit rawat inap RS berdasarkan fungsinya)

b. Rawat Jalan (Poliklinik, Perawatan Haemodialisa dan Instalasi Gawat Darurat atau IGD)

c. Kamar Operasi

Pengukuran timbulan limbah dilakukan selama tujuh hari berturut-turut dan diukur dalam kurun waktu per 24 jam dengan menyesuaikan waktu pengumpulan limbah di masing-masing RS Metode pengukuran timbulan limbah ini mengacu pada penelitian serupa sebelumnya ${ }^{(1,6)}$. Data sekunder penelitian ini yaitu data atribut RS yang terdiri atas jumlah pasien, jumlah staf medis dan 
data BOR untuk masing-masing unit RS. Data sekunder ini juga diambil selama tujuh hari berturut-turut yang menyesuaikan dengan data laju timbulan limbah. Data digunakan sebagai bagian dari analisis faktor timbulan limbah infeksius RS. Proses pengambilan data RS secara garis besar dapat dilihat pada Gambar 1.

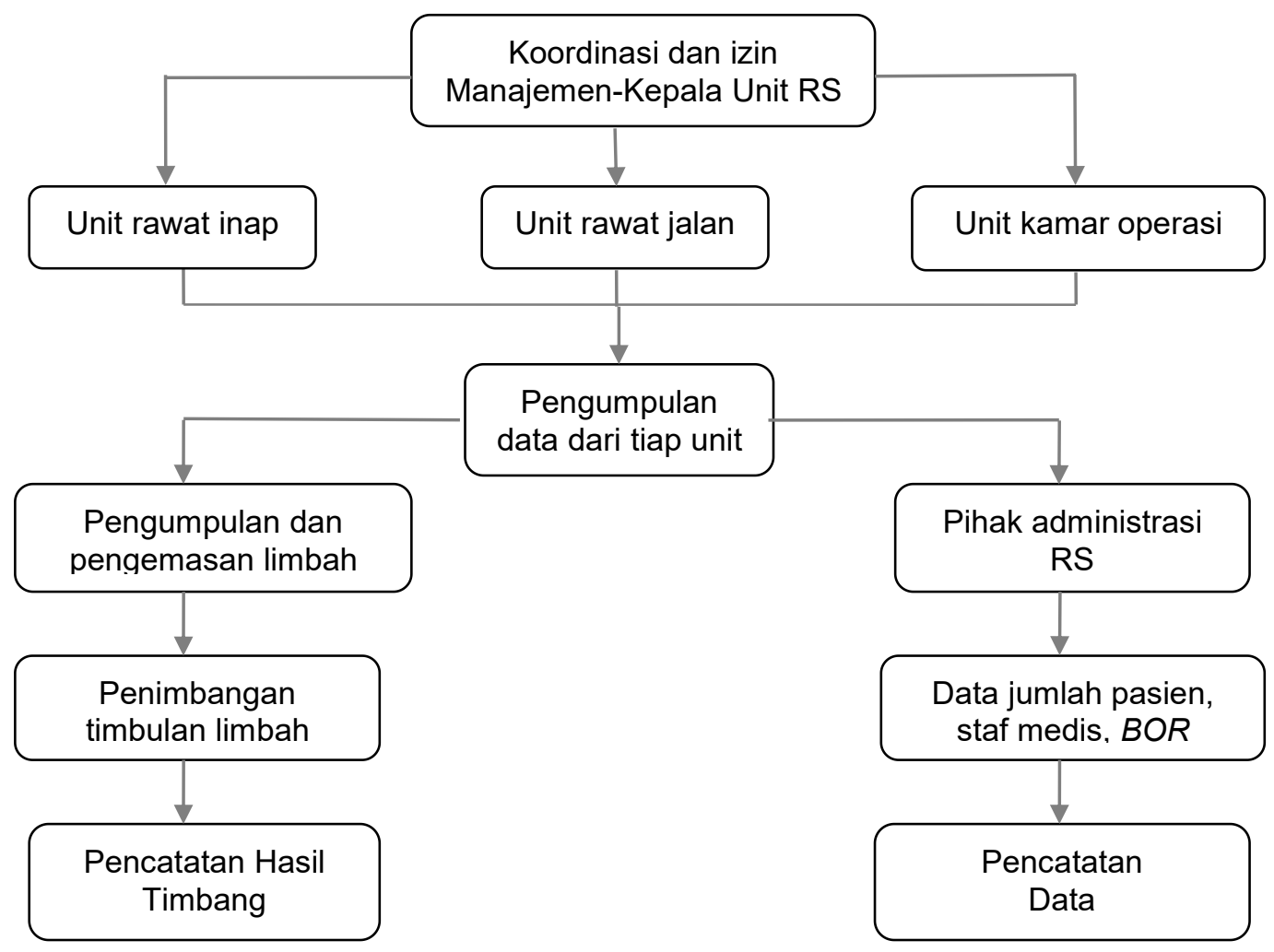

Gambar 1. Tahapan pengambilan data RS

\subsubsection{Analisis Data}

Analisis statistik inferensial khusus digunakan untuk mengkaji faktor yang paling berpengaruh terhadap besaran timbulan limbah infeksius. Jenis analisis tersebut ini ialah analisis statistik regresi bertatar. Analisis regresi bertatar atau yang lebih dikenal sebagai stepwise regression merupakan prosedur statistik untuk memilih variabel-variabel yang paling signifikan untuk dimasukkan ke dalam model regresi(8). Penelitian ini memiliki tiga faktor sebagai tiga variabel bebas (jumlah pasien, jumlah staf medis dan nilai BOR) yang akan dianalisis pengaruhnya secara bersama-sama terhadap besaran timbulan limbah infeksius dari tiap unit perawatan RS. Khusus nilai BOR, perhitungannya didasarkan pada Persamaan 3 berikut.

$$
\frac{\text { Jumlah pasien rawat inap }}{\text { Jumlah tempat tidur rawat inap }} \times 100 \% \ldots
$$

Variabel yang paling berpengaruh signifikan akan masuk menjadi bagian model regresi sedangkan yang tidak signifikan akan dikeluarkan. Software yang digunakan ialah
SPSS Statistics ver. 25.0 dengan nilai signifikansi 0,05 atau menggunakan Confidence Interval $(\mathrm{Cl})$ pada taraf 95\%. Gambar 2 menunjukkan gambaran proses analisis stepwise regression dengan diikuti model regresi yang terbentuk pada Persamaan 4.

$$
Y i=b_{0}+b_{1} X_{1} i+b_{2} X_{2} i+b_{3} X_{3} i+\varepsilon
$$

Keterangan :

$\mathrm{Yi}=$ variabel dependen (timbulan limbah nfeksius satuan $\mathrm{kg}$ )

$\mathrm{b0}=$ konstanta

b1 = koefisien regresi variabel independen 1 (jumlah pasien)

b2 = koefisien regresi variabel independen 2 (jumlah staf medis)

b3 = koefisien regresi variabel independen 3 (nilai BOR khusus variabel kegiatan rawat inap)

$\varepsilon=$ error pada $Y$

Jumlah variabel $\mathrm{b}$ dan $\mathrm{X}$ tergantung pada seberapa banyak faktor berpengaruh signifikan 


\section{HASIL DAN PEMBAHASAN}

\subsection{Persentase Timbulan Limbah Infeksius Secara Keseluruhan}

Limbah padat RS secara umum terbagi dua, limbah medis (infeksius) serta limbah umum (limbah non infeksius atau limbah domestik). Tabel 1 menunjukkan bahwa persentase timbulan limbah infeksius selalu lebih kecil dibandingkan limbah umum di RS. Hal ini sesuai dengan pernyataan $\mathrm{WHO}$ dan beberapa penelitian limbah padat $\mathrm{RS}^{(9,10)}$. Limbah umum yang dihasilkan RS didominasi dari kegiatan administrasi (alat tulis/ATK dan kemasan ATK), kegiatan farmasi (kemasan obat), dan kegiatan konsumsi (kemasan makanan/minuman). Di satu sisi, alat/bahan yang dimasukkan ke dalam wadah limbah infeksius yakni yang berasal dari perawatan pasien diantaranya plabot infus, jarum suntik, serta perban. Meskipun aktivitas utama RS adalah pelayanan kesehatan, tidak serta merta membuat limbah yang paling banyak dihasilkan adalah limbah kesehatan, terutama kategori infeksius. Hal ini dikarenakan pendefinisian dari limbah infeksius itu sendiri yang merupakan limbah yang sudah terkontaminasi darah dan cairan tubuh pasien (Peraturan Menteri Lingkungan Hidup RI Nomor 56 Tahun 2015). Berdasarkan Peraturan Menteri Kesehatan RI Nomor 4 Tahun 2018, pasien sendiri memiliki definisi yakni mereka yang melakukan konsultasi masalah kesehatannya untuk memperoleh pelayanan kesehatan yang diperlukan, baik secara langsung maupun tidak langsung di rumah sakit. Oleh karenanya, tidak semua orang yang berkunjung ke RS dikategorikan sebagai pasien. Namun demikian, porsi limbah infeksius yang lebih kecil dibandingkan limbah umum harus mendapatkan perhatian khusus oleh pihak RS dalam penangannya. Tujuannya, agar tidak menimbulkan masalah kesehatan baru akibat penanganan limbah infeksius yang kurang tepat.

Tabel 1. Persentase timbulan limbah padat RS

\begin{tabular}{ccc}
\hline \multirow{2}{*}{$\begin{array}{c}\text { RS } \\
\text { Sampel }\end{array}$} & \multicolumn{2}{c}{ Timbulan Limbah Padat (\%) } \\
\cline { 2 - 3 } & Limbah Infeksius & Limbah Umum \\
\hline A & 43 & 57 \\
\hline B & 47 & 53 \\
\hline C & 38 & 62 \\
\hline D & 47 & 53 \\
\hline
\end{tabular}

\subsection{Timbulan Limbah Infeksius Tiap Unit Perawatan RS}

Penanganan limbah infeksius dimulai dari melakukan kajian dari sumber pertama limbah tersebut dihasilkan. Dalam hal ini, sumber pertama tersebut ialah tiap unit perawatan di RS. Tabel 2 dan Tabel 3 masing-masing menunjukkan jenis limbah infeksius yang ada di unit perawatan (secara keseluruhan dari keempat RS) serta hasil rata-rata timbulan limbah infeksius selama tujuh hari pengukuran di masing-masing RS.

Tabel 2. Jenis limbah infeksius tiap unit perawatan RS

\begin{tabular}{|c|c|}
\hline $\begin{array}{c}\text { Unit } \\
\text { Perawatan }\end{array}$ & Jenis Limbah Infeksius \\
\hline \multicolumn{2}{|r|}{ Rawat Inap } \\
\hline Rawat Inap & $\begin{array}{l}\text { Plabot infus, kateter, jarum suntik, } \\
\text { kasa, kapas, perban, sarung } \\
\text { tangan dan masker disposable, } \\
\text { kemasan obat }\end{array}$ \\
\hline \multicolumn{2}{|r|}{ Rawat Jalan } \\
\hline Poliklinik & $\begin{array}{l}\text { Jarum suntik, kapas, kasa, perban, } \\
\text { tisu, spatel lidah kayu, sarung } \\
\text { tangan dan masker disposable }\end{array}$ \\
\hline Haemodialisa & $\begin{array}{l}\text { Kantong darah, kateter, selang } \\
\text { infus, jarum suntik, perban, kasa, } \\
\text { kapas, tisu, sarung tangan dan } \\
\text { masker disposable }\end{array}$ \\
\hline IGD & $\begin{array}{l}\text { Plabot infus, kateter, jarum suntik, } \\
\text { kasa, kapas, perban, sarung } \\
\text { tangan dan masker disposable }\end{array}$ \\
\hline \multicolumn{2}{|r|}{ Kamar Operasi } \\
\hline Kamar Operasi & $\begin{array}{l}\text { Jaringan tubuh, plabot infus, } \\
\text { kateter, kasa, kapas, perban, } \\
\text { sarung tangan, masker dan nurse } \\
\text { cap disposable, tisu, beberapa } \\
\text { benda tajam (scalpel, pisau, } \\
\text { gunting), benang operasi, kemasan } \\
\text { bahan kimia untuk operasi }\end{array}$ \\
\hline
\end{tabular}

Keterangan : limbah infeksius benda tajam seperti jarum suntik, scalpel, gunting, pisau, dan sejenisnya dimasukkan ke dalam wadah khusus yang disebut safety box. Warna safety box adalah kuning, menyesuaikan limbah infeksius

Unit perawatan RS secara garis besar dibagi menjadi tiga unit: rawat inap, rawat jalan dan unit (kamar) operasi. Ketiga jenis unit perawatan tersebut memiliki fungsi khusus sehingga terbagi lagi menjadi beberapa unit. Dari seluruh RS sampel, timbulan limbah infeksius yang paling tinggi secara umum berasal dari tiga unit perawatan: haemodialisa, kamar operasi serta rawat inap. Timbulan limbah infeksius dari unit perawatan haemodialisa berkisar $0,08-0,19$ $\mathrm{kg} /$ pasien haemodialisa/hari. Haemodialisa merupakan pengobatan (replacement treatment) pada pasien gagal ginjal kronik, sehingga fungsi ginjal pasien digantikan oleh alat yang disebut dyalizer (artifical kidney). Pada dialyzer ini terjadi proses pemindahan zat-zat terlarut dalam darah kedalam cairan dialisa atau sebaliknya(11). 
Limbah infeksius yang dihasilkan didominasi oleh kantong darah dan kateter (selang infus) yang masih berisikan darah pasien. Jenis limbah inilah yang menyumbang bobot besar bagi limbah haemodialisa, didukung dengan frekuensi satu orang pasien yang melakukan perawatan ini rata- rata satu hingga dua kali dalam seminggu dan minimal berlangsung selama tiga bulan secara berkelanjutan ${ }^{(11)}$. Haemodialisa juga disebutkan menjadi salah satu penghasil limbah medis terbesar $^{(12)}$.

Tabel 3. Timbulan limbah infeksius tiap unit perawatan dan keseluruhan RS

\begin{tabular}{|c|c|c|c|c|}
\hline \multirow[t]{2}{*}{ Unit Perawatan } & \multicolumn{4}{|c|}{$\begin{array}{c}\text { Timbulan Limbah Infeksius Tiap Unit Perawatan } \\
\text { (kg/pasien per unit/hari) }\end{array}$} \\
\hline & RS A & RS B & RS C & RS D \\
\hline \multicolumn{5}{|c|}{ Rawat Inap } \\
\hline Rawat Inap & 0,1 & 0,05 & 0,04 & 0,09 \\
\hline \multicolumn{5}{|c|}{ Rawat Jalan } \\
\hline Poliklinik & 0,01 & 0,01 & 0,002 & 0,03 \\
\hline Haemodialisa & 0,12 & 0,08 & 0,1 & 0,19 \\
\hline IGD & 0,04 & 0,01 & 0,02 & 0,02 \\
\hline \multicolumn{5}{|c|}{ Kamar Operasi } \\
\hline Kamar Operasi & 0,1 & 0,11 & 1,65 & 0,35 \\
\hline \multirow{2}{*}{$\begin{array}{l}\text { Timbulan Limbah Infeksius RS } \\
\text { (kg/pasien/hari) }\end{array}$} & RS A & RS B & RS C & RS D \\
\hline & 0,17 & 0,08 & 0,08 & 2,18 \\
\hline
\end{tabular}

Limbah infeksius dari kegiatan operasi dipengaruhi pula oleh jenis penyakit atau faktor yang menyebabkan operasi tersebut terjadi serta kondisi fisik pasien. Sebagai contoh untuk kasus melahirkan, pada umumnya dapat menghasilkan lebih banyak limbah karena banyaknya alat dan/atau bahan yang digunakan saat melakukan aktivitas operasi kelahiran ini. Hal ini terjadi pada RS D dimana terdata satu orang pasien yang melakukan operasi dapat menyumbang timbulan limbah infeksius mencapai $0,35 \mathrm{~kg}$ per hari. Pada kegiatan rawat inap, limbah infeksius pun tergolong besar jumlahnya $(0,05-0,1 \mathrm{~kg} /$ pasien rawat inap/hari) dikarenakan aktivitas perawatan dan pemeriksaan rutin pasien yang biasanya dilakukan dalam kurun waktu beberapa jam tertentu dalam satu hari. Di sisi lain, unit poliklinik serta IGD menjadi penyumbang limbah infeksius terendah. Pelayanan kesehatan yang diberikan kepada pasien poliklinik dan IGD lebih minim menggunakan alat/bahan yang langsung terkontaminasi cairan tubuh pasien, seperti stetoskop, termometer, tensimeter, dan alat luar tubuh lainnya. Penelitian serupa menyatakan bahwa limbah medis infeksius dari unit poliklinik dan IGD masing-masing hanya mencapai 0,01 dan 0,04 kg/pasien unit/hari(13). Berdasarkan hasil penelitian yang menunjukkan unit perawatan penghasil limbah infeksius terbesar RSU ialah unit haemodialisa, kamar operasi dan rawat inap, maka ketiga unit ini bisa dijadikan priroitas pengelolaan limbah infeksius RS.

\subsection{Faktor Timbulan Limbah Infeksius Tiap Unit Perawatan RS}

Dari keseluruhan bahasan hasil rata-rata timbulan limbah infeksius berdasarkan Tabel 3, faktor pasien menjadi faktor yang sangat berpengaruh terhadap tinggi-rendahnya timbulan limbah. Hal ini sejalan dengan beberapa penelitian lain yang mengungkapkan bahwa faktor pasien terhadap timbulan limbah infeksius memiliki korelasi yang sangat erat ${ }^{(1,2,6)}$. Selain faktor pasien, timbulan limbah infeksius dalam penelitian ini juga dikaji dari dua faktor penting lainnya, staf medis dan nilai BOR. Ketiga faktor ini dianalisis menggunakan stepwise regression berdasarkan jumlah dan nilai masing-masing variabel seperti yang tertera pada Tabel 4.

Sesuai dengan alur stepwise regression yakni memasukkan semua variabel bebas (ketiga faktor) untuk dianalisis pengaruhnya terhadap variabel terikat (timbulan limbah infeksius) ${ }^{(8)}$, kemudian memberikan hasil akhir faktor yang paling berpengaruh. Faktor yang paling berpengaruh tersebut memiliki nilai signifikansi dibawah $0,05(95 \% \mathrm{Cl})$. Hasil pada Tabel 5 menunjukkan bahwa tiap unit perawatan di tiap RS memiliki jenis faktor signifikan yang berbeda. Perbedaan kondisi di tiap tempat tersebut yang mendorong terjadinya perbedaan faktor yang dihasilkan. Faktor yang berpengaruh signifikan terhadap timbulan limbah infeksius berdasarkan Tabel 4 didominasi oleh faktor jumlah pasien. Pasien adalah objek layanan kesehatan RS, oleh karenanya sumber limbah $\mathrm{RS}$ adalah pasien. Nilai koefisien faktor jumlah pasien $\left(X_{1}\right)$ tunggal 
(data unit haemodialisa RS A dan kamar operasi RS D) berkisar antara 0,72 hingga 1,21 pada model regresi Tabel 5 dengan batasan $\mathrm{Cl} 0,34$ 2,03 . Hal ini dapat diinterpretasikan bahwa penambahan satu orang pasien dapat meningkatkan timbulan limbah infeksius sebanyak 1,21-2,03 $\mathrm{kg}$ limbah per harinya dan tidak kurang dari $0,34 \mathrm{~kg} / \mathrm{hari}$. Timbulan limbah infeksius salah satu RS umum di Indonesia dari berbagai unit perawatan mencapai 0,8 $\mathrm{kg} /$ pasien/hari(14) sampai dengan 1,98 $\mathrm{kg} /$ pasien/hari(13). Nilai $\mathrm{R}^{2}$ faktor jumlah pasien tunggal yaitu 0,2 sampai 0,8 dapat diartikan bahwa jumlah pasien mampu memengaruhi timbulan limbah infeksius sebesar $20-80 \%$, dimana sisanya timbulan limbah infeksius tersebut dipengaruhi oleh faktor di luar penelitian. Selain faktor jumlah pasien, faktor nilai BOR juga didapatkan signifikansi pengaruhnya di unit rawat inap RS A dan RS D. Nilai BOR yang merupakan indikator pelayanan RS menjadi faktor yang berpengaruh secara signifikan dikarenakan faktor jumlah beds adalah salah satu faktor yang signifikan berpengaruh pada produksi limbah infeksius rumah sakit ${ }^{(15)}$. Beds yang dimaksud merupakan bed (tempat tidur) bagi perawatan khusus pasien rawat inap. Karenanya, faktor BOR ini pun masih berkaitan erat dengan faktor jumlah pasien rawat inap.

Tabel 4. Jumlah pasien, staf medis dan nilai BOR tiap unit perawatan RS

\begin{tabular}{|c|c|c|c|c|}
\hline RS Sampel & Unit Perawatan & $\begin{array}{l}\text { Jumlah pasien } \\
\text { (orang/hari) }\end{array}$ & $\begin{array}{l}\text { Jumlah staf medis } \\
\text { (orang/hari) }\end{array}$ & $\begin{array}{c}\text { Nilai BOR } \\
\text { (\%/hari) }\end{array}$ \\
\hline \multirow{5}{*}{ RS A } & Rawat Inap & 12 & 9 & 52.28 \\
\hline & Poliklinik & 68 & 9 & - \\
\hline & IGD & 28 & 11 & - \\
\hline & Haemodialisa & 18 & 6 & - \\
\hline & K. Operasi & 9 & 10 & - \\
\hline \multirow{5}{*}{ RS B } & Rawat Inap & 20 & 13 & 64,51 \\
\hline & Poliklinik & 46 & 17 & - \\
\hline & IGD & 113 & 16 & - \\
\hline & Haemodialisa & 40 & 11 & - \\
\hline & K. Operasi & 21 & 14 & - \\
\hline \multirow{5}{*}{ RS C } & Rawat Inap & 7 & 10 & 50,50 \\
\hline & Poliklinik & 67 & 43 & - \\
\hline & IGD & 11 & 11 & - \\
\hline & Haemodialisa & 30 & 16 & - \\
\hline & K.Operasi & 14 & 14 & \\
\hline \multirow{5}{*}{ RS D } & Rawat Inap & 10 & 11 & 49,02 \\
\hline & Poliklinik & 68 & 38 & - \\
\hline & IGD & 47 & 15 & - \\
\hline & Haemodialisa & 15 & 6 & - \\
\hline & K. Operasi & 4 & 9 & - \\
\hline
\end{tabular}

Keterangan: Faktor BOR diperuntukkan khusus untuk unit perawatan rawat inap

Di satu sisi, faktor pasien ini juga dapat meningkatkan kecenderungan terjadinya kesalahan dalam hal pemilahan limbah infeksius dengan limbah umum. Hal ini dikarenakan tidak seluruh pasien, termasuk kerabat pasien (pengunjung RS), paham dan familiar tentang benda apa saja yang dapat dibuang dalam wadah limbah berwarna kuning. Kondisi ini riil terjadi saat peneliti melakukan observasi lapangan dan berdasarkan informasi dari pihak pengelola limbah RS. Maka dari itu, pihak RS perlu untuk meminimalisir terjadinya kesalahan pemilahan yang sewaktu-waktu dapat dilakukan oleh pasien tersebut diantaranya dengan pemasangan poster penjelasan limbah infeksius pada tempat-tempat yang mudah terbaca oleh pasien dan pengunjung, pemberian keterangan dengan jelas pada label wadah limbah infeksius, ataupun pengaturan posisi wadah limbah infeksius agar tidak terlalu mudah terjangkau oleh pasien. Salah satu RS di negara berkembang menerapkan sebuah cara agar tidak terjadi kesalahan pemilahan oleh pasien dengan meniadakan wadah limbah medis dan infeksius di area akses pasien. Wadah yang tersedia di area pasien dan area terbuka RS tersebut hanyalah wadah limbah domestik. Cara ini terbukti efektif untuk meminimalisir kesalahan pemilahan tersebut ${ }^{(16)}$. 
Tabel 5. Faktor signifikan timbulan limbah infeksius RS

\begin{tabular}{|c|c|c|c|c|c|}
\hline $\begin{array}{c}\text { RS } \\
\text { Sampel }\end{array}$ & $\begin{array}{c}\text { Unit } \\
\text { Perawatan }\end{array}$ & $\begin{array}{l}\text { Faktor } \\
\text { Signifikan }\end{array}$ & Model Regresi & $95 \% \mathrm{Cl}$ & Nilai $\mathbf{R}^{2}$ \\
\hline \multirow{5}{*}{$A$} & Rawat Inap & Nilai BOR & $Y=6,29+0,006 X+\varepsilon$ & 0,02 s.d 0,11 & 0,15 \\
\hline & \multirow[b]{2}{*}{ Poliklinik } & \multirow{2}{*}{$\begin{array}{l}\text { Jumlah Pasien \& } \\
\text { Staf Medis }\end{array}$} & \multirow[b]{2}{*}{$Y=1,77 \times 10^{-15}+0,13 X_{1}-0,9 X_{2}+\varepsilon$} & $X_{1}: 0,08$ s.d 0,18 & \multirow[b]{2}{*}{0,96} \\
\hline & & & & $\begin{array}{c}\mathrm{X}_{2}:(-1,13) \text { s.d }(- \\
0,25)\end{array}$ & \\
\hline & Hemodialisa & Jumlah Pasien & $Y=2,79+0,72 X_{1}+\varepsilon$ & 0,34 s.d 1,09 & 0,83 \\
\hline & $\begin{array}{l}\text { Kamar } \\
\text { Operasi }\end{array}$ & $\begin{array}{c}\text { Jumlah Staf } \\
\text { Medis }\end{array}$ & $Y=1,57+0,99 X_{2}+\varepsilon$ & 1,26 s.d 1,88 & 0,97 \\
\hline \multirow{3}{*}{$B$} & \multirow{2}{*}{ Rawat Inap } & \multirow{2}{*}{$\begin{array}{c}\text { Jumlah Pasien \& } \\
\text { Staf Medis }\end{array}$} & \multirow{2}{*}{$Y=0,39+0,09 X_{1}+0,48 X_{2}+\varepsilon$} & $X_{1}: 0,01$ s.d 0,18 & \multirow{2}{*}{0,18} \\
\hline & & & & $X_{2}: 0,25$ s.d 0,70 & \\
\hline & Hemodialisa & $\begin{array}{l}\text { Jumlah Staf } \\
\text { Medis }\end{array}$ & $Y=10,39+1,17 X_{1}+\varepsilon$ & 0,006 s.d 2,34 & 0,57 \\
\hline \multirow{3}{*}{$\mathrm{D}$} & \multirow[b]{2}{*}{ Rawat Inap } & \multirow[b]{2}{*}{$\begin{array}{c}\text { Jumlah Pasien \& } \\
\text { Nilai BOR }\end{array}$} & \multirow[b]{2}{*}{$Y=5,31+0,81 X_{1}-0,14 X_{3}+\varepsilon$} & $X_{1}: 0,40$ s.d 1,13 & \multirow[b]{2}{*}{0,26} \\
\hline & & & & $\begin{array}{c}X_{2}:(-0,26) \text { s.d } \\
(-0,014)\end{array}$ & \\
\hline & $\begin{array}{l}\text { Kamar } \\
\text { Operasi }\end{array}$ & Jumlah Pasien & $Y=5,44+1,21 X_{1}+\varepsilon$ & 0,40 s.d 2,03 & 0,47 \\
\hline
\end{tabular}

Keterangan : $\mathrm{X}_{1}=$ Jumlah pasien, $\mathrm{X}_{2}=$ Jumlah staf medis, $\mathrm{X}_{3}=$ Nilai BOR, $\varepsilon=$ Error, s.d = "sampai dengan" (merujuk pada batas bawah sampai dengan batas atas $95 \%$ Confidence Interval tiap variabel signifikan)

Faktor jumlah staf medis juga berpengaruh signifikan di beberapa unit perawatan seperti poliklinik dan kamar operasi RS A serta unit rawat inap dan haemodialisa RS B. Faktor staf medis ini dapat bersifat signifikan secara tunggal, maupun signifikan bersama faktor jumlah pasien. Dengan demikian, dapat dilihat ada keterkaitan yang erat antara staf medis dan pasien. Staf medis (perawat) merupakan perantara antara pasien dan petugas kebersihan dalam hal pengelolaan limbah infeksius ${ }^{(17)}$. Sumber utama limbah infeksius adalah pasien, namun staf medis juga memegang peranan yang besar sebagai penyumbang limbah infeksius karena staf medis yang pada dasarnya menjadi pemilah utama limbah tersebut. Artinya, saat staf medis telah melakukan perawatan terhadap pasien, sisa alat/bahan dari perawatan tersebut dikumpulkan kemudian dimasukkan ke wadah limbah infeksius oleh staf medis itu sendiri. Faktor jumlah staf medis juga bisa berbanding lurus secara signifikan, dimana semakin banyak staf medis, timbulan limbah infeksius yang dihasilkan juga bisa semakin tinggi. Sebagai contoh dari model regresi unit haemodialisa RS B pada Tabel 5, satu orang staf medis bisa menghasilkan hingga 1,17 $\mathrm{kg}$ limbah infeksius per harinya. Oleh karenanya, peran dan tanggung jawab staf medis yang besar terhadap pemilahan limbah infeksius di RS harus menjadi perhatian khusus oleh pengelola RS. Salah satunya dengan pemberian training rutin terkait pengelolaan limbah rumah sakit kepada para staf medis tersebut. Training dapat menjadi wadah dan sarana yang tepat agar para staf medis mampu meningkatkan keterampilan dan pengetahuannya serta mengubah sikap, perilaku dan mindset-nya. Pengetahuan dan pemahaman yang baik dan benar terkait jenis limbah medis di rumah sakit adalah langkah paling awal dalam keefektifan pengelolaan limbah $\mathrm{RS}^{(18)}$.

\section{KESIMPULAN}

Limbah infeksius memiliki persentase timbulan yang lebih kecil dibandingkan limbah umum (non-infeksius atau limbah domestik) di RS. Namun demikian, pengelolaan limbah infeksius yang tepat tetap harus dilakukan pihak RS agar tidak menimbulkan risiko terhadap kesehatan manusia dan lingkungan. Berdasarkan hasil penelitian keseluruhan, rata-rata timbulan limbah infeksius RS berkisar 0,08 sampai 2,18 $\mathrm{kg} /$ pasien/hari dengan penghasil terbesar didominasi dari unit perawatan haemodialisa, kamar operasi, dan rawat inap. Oleh karenanya, ketiga unit perawatan ini dapat menjadi prioritas atau fokus khusus pihak RS dalam hal pengelolaan limbah infeksius. Adapun faktor yang signifikan berpengaruh terhadap timbulan limbah infeksius RS didominasi oleh faktor jumlah pasien serta jumlah staf medis. Kedua faktor ini juga perlu dikelola khusus agar tidak menjadi bumerang terhadap timbulan limbah infeksius itu sendiri, terutama dalam hal pemilahan limbah. Cara pengelolaan tersebut dapat berupa pengaturan wadah limbah infeksius di area akses pasien serta pemberian training untuk meningkatkan pengetahuan dan keterampilan terkait pemilahan limbah infeksius bagi para staf medis. 


\section{PERSANTUNAN}

Penulis menyampaikan terima kasih kepada pihak rumah sakit umum yang telah memberikan izin pengambilan data penelitian. Tidak ada peran pihak luar dalam hal pendanaan serta tidak ada potensi konflik kepentingan terkait kegiatan penelitian maupun penulisan naskah.

\section{DAFTAR PUSTAKA}

1. Debere, M.K., Gelaye, K.A., Alamdo, A.G., \& Trifa, Z.M. (2013). Assessment of the health care waste generation rates and its management system in hospitals of Addis Ababa, Ethiopia, 2011. BMC Public Health, 13(28), 1-9.

2. Wahab, A.B \& Adesanya, D.A (2011). Medical waste generation in hospitals and associated factors in Ibadan Metropolis, Nigeria. Research Journal of Applied Sciences, Engineering and Technology, 3, 746-751.

3. Fitria, N., Damanhuri, E. \& I.R.S Salami (2017). Assessment of infectious waste management practices at hospital with "Paripurna" accreditation level in Bandung, Cimahi, and East Jakarta, Indonesia. The Third International Conference on Sustainable Infrastructure and Built Environment (SIBE), 1-14.

4. Amasuomo, E. \& Baird, J. (2016). The concept of waste and waste management. Journal of Management and Sustainability, 6(4), 88-96.

5. Eslami, A., Nowrouz, P., \& Sheikholeslami, S. (2017). Status and challenges of medical waste management in hospitals of Iran. Civil Engineering Journal, 3(9), 741-748.

6. Hayleeyesus, S.F \& Cherinete, W. (2016). Healthcare waste generation dan management in public healthcare facilities in Adama, Ethiopia. Journal of Health \& Pollution, 6(10), 64-73.

7. Dias, G.L., Sarturi, F., Camponogara, S., de Lima, S.B.S., Lopes, L.F.D \& Trevisan, C.M. (2017). Analysis of the medical waste production rate in teaching hospital. J. Res. Fundam.care, 9(1), 92-98.

8. Wang, G.C.S \& Jain, C.L. Regression analysis : modelling dan forecasting. New York: Graceway Publishing Company, 2003.
9. Lisafitri Y., Rahmawati, N., Pertiwi, R.F., \& Prasetio, B. (2017). Evaluation of hospital's obedience in medical solid waste management. Journal of Multidisciplinary Academic, 1(1), 21-24.

10. Purwanti, A.A. (2018). Pengelolaan limbah padat bahan berbahaya dan beracun (B3) rumah sakit di RSUD Dr. Soetomo Surabaya. Jurnal Kesehatan Lingkungan, 10(3), 291298.

11. Wiliyanarti, P.F., \& Muhith, A. (2019). Life experience of chronic kidney diseases undergoing hemodialysis therapy. NurseLine Journal, 4(1), 54-60.

12. Piccoli, G.B., Cupisti, A., Aucella, F., Regolisti G., Lamonte, C., Ferraresi, M., Caludia, D., Ferraresi, C., Russo, R., La Milia, V., Covella, B., Rossi, L., Chatrenet, A. Cabiddu, \& G., Brunori, G. (2020). Green nephrology and eco-dialysis : a position statement by the Italian society of nephrology. Journal of Nephrology, 33, 681-698.

13. Wulandari, P., \& Kusnoputranto, H. (2015). Medical waste management and minimization efforts at public hospital. Case study : public hospital in East Jakarta, Indonesia. KESMAS, 9(2), 77-84.

14. Saghita, E.P., Thamrin \& Afandi, D. (2017) Analisis minimasi limbah padat medis di RS PB. Jurnal Photon, 7(2), 1-7.

15. Cheng, Y.W., Sung, F.C., Yang, Y., Lo, Y.H., Chung, Y.T., \& Li, K.C. (2009). Medical waste production at hospitals and associated factors. Waste Management, 29(1), 440-446.

16. Saptoka, B., Gupta, G.K., \& Mainali, D. (2014). Impact of intervention of healthcare waste management practices in a tertiary care governmental hospital of Nepal. BMC Public Health, 14, 1-8.

17. Ali, M., Wang, W., \& Chaudhry, N. (2016). Investigating motivating factors for sound hospital waste management. Journal of the air and waste management association, 66(8), 784-794.

18. Maina, J.W. (2018). Knowledge, attitude and practice of staf on segregation of hospital waste : a case study of a tertiary private hospital in Kenya. European Scientific Journal, 14(9), 401-417. 